\title{
Screening for sources of tolerance to drought in sesame induced mutants: Assessment of indirect selection criteria for seed yield
}

\author{
Boureima $^{1 *}$ S., Diouf ${ }^{2}$ M., Amoukou ${ }^{3}$ A.I. and Van Damme ${ }^{4}$ P. \\ ${ }^{1}$ Faculté d'Agronomie et des Sciences de l'Environnement, \\ Université Dan Dicko Dankoulodo de Maradi, BP 465, Maradi, Niger \\ 2 Institut Sénégalais de Recherches Agricoles \\ ${ }^{3}$ Faculté d'Agronomie, Université Abdou Moumouni \\ ${ }^{4}$ Faculty of Bioscience Engineering, Ghent University, Belgium \\ *Corresponding Author E-mail: boureimaseyni@yahoo.fr \\ Received: 09.02.2016 | Revised: 16.02.2016 | Accepted: 21.02.2016
}

\begin{abstract}
In African sub-Saharan countries, sesame is mostly grown under rain fed conditions where it is subjected to drought stress. The objective of this study was to identify the drought tolerance sources in induced-mutants of sesame. Sixteen induced mutants and their three respective parental sources were evaluated in separate experiments under drought stress and normal conditions in the field over two years (2010 and 2011). Seven drought tolerance indices including stress susceptibility index (SSI), stress tolerance index (STI), mean productivity (MP), geometric mean productivity (GMP), tolerance (TOL), yield index (YI) and yield stability index (YSI) were calculated based on yield under drought $\left(Y_{s}\right)$ and yield in optimal conditions $\left(Y_{p}\right)$. Factor analysis $(F A)$ evidenced that first and second factors accounted for 98.7 and $98.5 \%$ of the variation in the first and second year, respectively. Biplot and FA evidenced that genotypes LC 164, LC 162, BC 167, EF 147 and MT 169 had the highest grain yield under both DS and NS environments in 2010, whereas in 2011 the best performers in both environments were HC 108, 32-15, HB 168 and 38-1-7. FA and the mean rank method discriminated genotypes LC 164, LC 162 and BC 167 as the most drought-tolerant in 2010 whereas in 2011 the combined methods identified 32-15 as the highest drought-tolerant genotype. Plant height, the number of capsules per plant, and the length of the capsules should be considered in selection for obtaining high-yielding sesame cultivars in drought-stressed environments.
\end{abstract}

Key words: Sesamum indicum L., drought stress, yield, criteria.

\section{INTRODUCTION}

Sesame (Sesamum indicum L., Pedaliaceae) is also called orphan crop. Nowadays, however world demand for its seeds is interestingly increasing owing to its good quality oil (50\%), protein $(25 \%)$ and for content of antioxidants ${ }^{3,11,33}$. Beside these nutritional benefits, sesame cropping has many agricultural advantages: it grows well in tropical to temperate climates, it can grow on stored soil moisture without the need for rainfall or irrigation, and be grown in pure stands with low input, or else in mixed stands with diverse crops ${ }^{4}$.

Cite this article: Boureima, S., Diouf, M., Amoukou, A.I. and Damme, V.P., Screening for sources of tolerance to drought in sesame induced mutants: Assessment of indirect selection criteria for seed yield, Int. J. Pure App. Biosci. 4(1): 45-60 (2016). doi: http://dx.doi.org/10.18782/2320-7051.2218 
Despite the many advantages of sesame seeds, less attention is dedicated to the crop by research centers so that genetic and breeding improvement efforts in sesame have been limited making the results of such efforts slow to emerge. Ashri ${ }^{4}$ stated that the main reason for this limited success is that sesame is a crop mainly produced in developing countries and usually by smallholders. The total world production was about 4756751 tones from a planted area of 9 million hectares in 2013 and the average yields ranged from $385 \mathrm{~kg} \mathrm{ha}^{-1}$ in 2000 to $506 \mathrm{~kg} \mathrm{ha}^{-1}$ in $2013^{12}$. Despite the high yield potential of sesame, actual yields are quite low due to a combination of biotic and abiotic stresses.

The main sesame grower countries are India, Myanmar and Sudan, most growing areas are classed as arid or semi-arid ${ }^{12}$ and in these regions, sesame is subjected to terminal and intermittent droughts. In these drought prone environments, breeders' primary interest is in grain yield which may be considered to be affected by three components including yield potential, appropriate phenology and drought tolerance ${ }^{24}$. To achieve high and durable yield in such environments drought-tolerant genotypes are needed. Unfortunately, the development of improved sesame cultivars for drought tolerance is hampered by the lack of efficient selection criteria. Two classical methods are usually followed to select for drought tolerance in crops: (i) utilization of grain yield as direct selection criteria, and (ii) indirect selection based on secondary traits ${ }^{26}$ which are plant characteristics that are associated with yield, and they can provide additional information for breeders to use when they make selections ${ }^{20}$.

Although some authors reported positive correlation between yield in optimal conditions and yield under drought $^{1,8,17,22}$, direct selection based on yield potential or mean yield under non-stress conditions may be misleading for the selection of drought-tolerant genotypes because drought tolerance is a complex quantitative trait, involving interactions of many metabolic pathways related to stress tolerance genes ${ }^{1}$.

The identification of a standard evaluation assay has been the most pressing problem for the selection of drought-tolerant genotypes ${ }^{18}$. Different indices have been employed for selecting drought-tolerant genotypes. Rosielle and Hamblin ${ }^{25}$ defined stress tolerance (TOL) as the difference between yields under optimal $\left(\mathrm{Y}_{\mathrm{p}}\right)$ and stress conditions $\left(\mathrm{Y}_{\mathrm{s}}\right)$ and the mean productivity (MP) as the average yield between $\mathrm{Y}_{\mathrm{s}}$ and $Y_{p}$. Fischer and Maurer ${ }^{15}$ proposed a stress susceptibility index (SSI) and Fernandez ${ }^{14}$ introduced a stress tolerance index (STI) as a selection criterion to identify genotypes with high yield and stress tolerance potentials. The latter author stated that MP has an upward bias due to a relatively larger difference between $Y_{p}$ and $Y_{s}$ and proposed a novel index, the geometric mean productivity (GMP) which is less sensitive to large extreme values.

All these indices are based on grain yield though, it is useful to screen for secondary traits as well because grain yield under drought is a complex quantitative trait whose repeatability is low relative to yield in non-stress environments, reducing selection efficiency ${ }^{16}$. Also, high-yielding cultivars in well-watered conditions are not necessarily the top performers in drought-stressed conditions. Hence much effort has been focused on the genetic analysis of secondary traits. In a drought breeding program, secondary traits are valuable for many reasons: If observed before or at flowering, they can be used for selecting desirable crossing parents; if observed before maturity, they can be used for preliminary selection.

Bänziger and Lafitte ${ }^{5}$ reported that secondary traits can help to improve the precision with which droughttolerant genotypes are identified, compared to measuring only grain yield under drought. Therefore, the understanding of the relationship between yield and secondary traits is crucial for developing an adequate breeding program and this relationship is traditionally explained by means of correlation, regression and path coefficient analyses ${ }^{29,30,38}$. Path coefficient analysis ${ }^{36}$ is helpful in partitioning the direct and indirect contribution of yield components to seed yield ${ }^{29}$ and gives more realistic relationship between characters than the phenotypic correlation.

The objective of this study was to evaluate and select high yielding sesame genotypes and identify secondary traits to be used as selection criteria for seed yield under both drought and optimal conditions. Phenotypic correlations, path coefficients and factor analysis will be used for this assessment. 


\section{MATERIALS AND METHODS}

\section{Germplasm and location}

The experiments were carried out with 19 sesame lines at the experimental station of the Centre National de Recherche Agronomique (CNRA), Bambey, Senegal (latitude $14^{\circ} 42^{\prime}$ North and longitude $16^{\circ} 28^{\prime}$ West) during the dry season of 2010 (04 November 2010 to January 25, 2011) and the wet cropping season of 2011 (July, 01-November, 30). These lines included 16 gamma-ray-induced mutants and their three respective parental sources: 32-15; 38-1-7 and Birkan. Mutants were induced in 2008 using 300 and 400 Gy gamma rays doses irradiating seeds of the three mother sources cited above. These mutants were confirmed in 2009 and $2010^{7,10}$. Cultivars 32-15 and 38-1-7 belonged to the sesame germplasm collection of the Institut Sénégalais de Recherches Agricoles (ISRA) and are widely grown by senegalese sesame growers for their rusticity and their marketable seeds' value (white seeds). Cultivar Birkan is a nonphotosensitive mutant-cultivar introduced from the Faculty of Agriculture, Akdeniz University (Turkey).

\section{Experimental design and set-up}

In both 2010 and 2011, the layout was a factorial design consisted of adjacent non-stressed (NS) and drought-stressed (DS) blocks separated by a buffer of $10 \mathrm{~m}$ to prevent lateral movement of water from the NS to the DS plots. Within each block, plants were assigned to experimental plots using a randomized complete block design with three replications. Each plot consisted of four rows, spaced $0.6 \mathrm{~m}$ apart with $0.20 \mathrm{~m}$ between plants in the row. Row length was $4 \mathrm{~m}$ in both years. All trials were established in the field and plots were kept free from weeds, diseases and insects pests by a combination of preventive chemicals treatments (Decis, $1 \mathrm{ml}^{1^{-1}}$ ) and hand labour.

Prior to seeding, the soil was ploughed at a $15 \mathrm{~cm}$ depth. A composite N-P-K fertilizer (15-15-15) was applied at a rate of $80 \mathrm{~kg} \mathrm{ha}^{-1}$ before sowing. In the dry season of 2010-2011 (04 November 2010 to January 25, 2011), plots were irrigated with $40 \mathrm{~mm}$ water one day prior to seeding using an oscillating ramp system. After emergence, both NS and DS blocks were irrigated with $20 \mathrm{~mm}$ of water twice a week until flowering time. Thereafter, DS plots did not receive water until harvest, whereas NS plants were kept well watered by receiving $20 \mathrm{~mm}$ of water twice a week until physiological maturity. Non-stressed plots received a total amount of $460 \mathrm{~mm}$ water, while DS plots had received a total of $180 \mathrm{~mm}$ before flowering.

Environmental data, including daily rainfall $(\mathrm{mm})$, minimum and maximum temperatures $\left({ }^{\circ} \mathrm{C}\right)$ and relative air humidity (\%) were obtained from an automated weather station (Hobo H21-002) placed on the experimental site. The minimum air temperature and humidity were $13.4{ }^{\circ} \mathrm{C}$ and $8 \%$, respectively and the maximum were $39.1{ }^{\circ} \mathrm{C}$ and $100 \%$, respectively.

In the 2011 wet cropping season, NS plots were sown in July as normal planting. To simulate a terminal drought, DS plots were planted with a delay of two months (September, 5). In all DS plots, $50 \%$ flowering occurred between October, 9 and 15. After this period, no rainfall was recorded until crop maturity. Total rainfall was $584.2 \mathrm{~mm}$ in NS plots while DS plots received $159.9 \mathrm{~mm}$ before flowering. The minimum air temperature and humidity were $15.5^{\circ} \mathrm{C}$ and $13 \%$, respectively and the maximum were $40.4^{\circ} \mathrm{C}$ and $100 \%$, respectively.

In both seasons, data were recorded for plant height $(\mathrm{PH})$, height to the first capsule on the main stem (SLFC), number of branches per plant (NB), number of capsules per plant (NCP), number of seed per capsule (NSC), capsule length (LC), 1000-seed weight (SW) and seed yield. For seed yield measurement, $2.4 \mathrm{~m}^{2}$ where harvested from the two central rows. Prior to harvesting, the first two plants at the borders of the row were discarded.

In addition, the drought intensity index (DII) defined by Fischer and Maure ${ }^{15}$ was determined for each season.

$D I I=\frac{1-X_{d s}}{X_{n s}}$, where $\mathrm{X}_{\mathrm{ds}}$ and $\mathrm{X}_{\mathrm{ns}}$ are the mean yields of all genotypes under drought-stressed and nonstressed conditions, respectively. 
The stress susceptibility index (SSI) was calculated according to Fischer and Maurer ${ }^{15}$ and the stress tolerance index (STI) was determined for each genotype following Fernande $z^{14}$ :

$$
S S I=\frac{\left(\frac{1-Y_{s}}{Y_{p}}\right)}{D I I} \text {, where } \mathrm{Y}_{\mathrm{s}} \text { and } \mathrm{Y}_{\mathrm{p}} \text { are the mean yields of a given genotype in DS and NS environments, }
$$
respectively.

$S T I=\frac{Y s \times Y p}{X_{p}{ }^{2}}$,where $\mathrm{X}_{\mathrm{p}}$ is the mean yield of all genotypes under non-stressed conditions.

Geometric mean productivity (GMP) was calculated for seed yield according to Fernandez ${ }^{14}$ :

$G M P=\sqrt{(Y s \times Y p)}$

Data were analyzed using MINITAB statistical program by one-way ANOVA and test. Differences between mean values of treatments were evaluated using least significant difference (LSD) at a 0.05 significance level. Path coefficient and phenotypic correlation analyses were carried out to determine the relationship between the traits studied and their direct and indirect contribution to seed yield ${ }^{9}$.

\section{RESULTS}

Variation in yield and yield components under non-stressed (NS) and drought-stressed (DS) environments

For both years, the results of ANOVA showed significant differences between genotypes in respect to yield and yield components under normal and drought stress conditions (Tables $1 \& 2$ ) except for plant height and number of branches in 2010 and for number of capsules per plant in 2011 in drought stress conditions.

Comparison of means grain yield per genotypes indicated that in well watered conditions (NS) HB 168 in 2010 and 38-1-7, HB 168, and 32-15 in 2011 had the highest grain yield while Birkan, MC 114 in 2010; MT 169 in 2011 had the lowest yield. In drought stress conditions (DS), LC 164 and LC 162 in 2010; HC 107 in 2011 had the highest yield while MC 114 had the lowest in both years (Tables $1 \& 2$ ). The range in yield under normal and drought stress conditions showed that there is a genotypic variability between genotypes for productivity.

In 2010, genotypes LC 164, LC 162, BC 167, EF 147 and MT 169 had the highest grain yield under both DS and NS environments while ICN 130, MC 112, 32-15, ICN 115, HC 107, Birkan, and MC 114 had the lowest grain yields under both DS and NS conditions (Table 1, Fig. 1a). HC 108, SHI 165 and EF 153 had the highest grain yields only in DS environment in contrast to VGR 156, 38-1-7, HSC 105 and HB 168 which were the best performers only in NS environment.

In 2011, HC 108, 32-15, HB 168 and 38-1-7 had the highest grain yield under both DS and NS conditions. In contrast MT 169, MC 112, EF 147, SHI 165, and MC 114 had the lowest grain yield in both DS and NS conditions (Table 2, Fig. 1b). HC 107, LC 162, LC 164, HSC 105, and ICN 115 had the highest grain yields in DS environments while Birkan, VGR 156, BC 167, ICN 130 and EF 153 revealed higher grain yields only in NS conditions (Table 2, Fig. 1b).

\section{Stress tolerance indices and selection for drought resistance}

To evaluate 19 sesame genotypes for drought tolerance, seven selection indices (SSI, STI, MP GMP, TOL, YI and YSI) were used. STI, MP, GMP and YI had significant positive correlation with both yield 
under drought-stressed $\left(\mathrm{Y}_{\mathrm{s}}\right)$ and yield under non stressed environments in both two years but there is no correlation between $\mathrm{YI}$ and $\mathrm{Y}_{\mathrm{p}}$ in 2011 (Table 3 \& 4). YI had the highest correlation $\left(\mathrm{r}=1^{* *}\right.$ in both years) with $Y_{s}$, whereas MP had the highest correlation with $Y_{p}\left(r=0.87^{* *}\right.$ and $r=0.94 * *$, for 2010 and 2011, respectively).

The correlation between $Y_{p}$ and $Y_{s}$ was positively significant $\left(r=0.49^{*}\right)$ in 2010 but not significant at all in 2011. SSI and TOL were negatively correlated with Ys even though this correlation is not significant in the year 2011 (Table 4).

The estimates of drought tolerance attributes based on a single criterion are contradictory. In the 2010 trial and according to STI, MP and GMP genotypes LC 164, LC 162 and HB 168 were the most droughttolerant genotypes whereas MC 114, Birkan and MC 112 were the most sensitive ones during the season 2010 (Table 5). Based on TOL scores HC 108, LC 164 and SHI 165 were the most desirable drought tolerant genotypes and HB 168, HSC 105 and 38-1-7 the most sensitive genotypes. According to SSI and YSI the desirable drought-tolerant genotypes were HC 108, BC 167 and SHI 165 (Table 5).

The same contradiction was highlighted in the 2011 cropping season when suitable drought-tolerant genotypes were selected based on a single drought tolerance index (Table 6).

The mean rank and standard deviation of ranks of all drought tolerance criteria were calculated and based on these two criteria the most desirable drought tolerant genotypes were identified. In consideration to all indices genotypes LC 164, LC 162 and BC 167 exhibited the best mean rank and low standard deviation of ranks (Table 5) under drought-stressed environment in 2010, hence they were considered as the suitable drought tolerant genotypes.

In 2011, LC 162, 32-15, HB 168 and HC 108 had the best mean rank and low standard deviation (Table 6) and were identified as the most drought tolerant genotypes.

Genotype LC 162 could therefore be identified as the best drought tolerant material, while MC 114 was the most sensitive for both years.

To use all indices simultaneously, factor analysis was also carried out. The two first factors explained $98.7 \%$ and $98.5 \%$ of the total variance in 2010 and 2011, respectively (Table 7). The relationship between the genotypes and all the drought tolerance indices is plotted in the same graph (Fig 2a \& 2b). The first factor (FA1) was highly and positively correlated with $Y_{p}$, STI, MP and GMP in both years (Table). YI and $\mathrm{Y}_{\mathrm{s}}$ were positively correlated by the first factor in 2010. Therefore, FA1 in both years was named as drought tolerance.

The second factor (FA2) was represented by SSI, TOL and YSI in 2010 and by $\mathrm{Y}_{\mathrm{s}}$, YI, STI, MP and GMP in 2011. SSI, TOL, YS, STI, MP, GMP and YI had negative coefficient with FA2. Thus the higher scores for FA1 and FA2 in 2010 were in accordance with higher drought tolerance while in 2011 it's higher score for FA1 and lower scores for FA2 which may be considered as higher drought tolerance. The sum of two first factors (FA1+FA2) are presented in Tables 5 and 6, respectively.

Coefficients of direct and indirect effects of path analysis in drought-stressed conditions are shown in Table 8. The number of capsules per plant had the highest positive and direct effect $(p=0.519)$ on seed yield in drought conditions. This trait was followed by plant height $(\mathrm{p}=0.332)$, thousand seeds weight $(\mathrm{p}$ $=0.276)$, length of the capsule $(p=0.233)$ and number of seeds per capsule $(p=0.176)$. The stem length to the first capsule had negative direct effect $(-0.283)$ on seed yield under drought-stressed conditions. The height of the Plant had the highest indirect effect (0.348) on seed yield via the number of capsules per plant. Similarly, the number of capsules per plant had a positive indirect effect $(0.223)$ via plant height on seed yield followed by stem length to the first capsule (0.221) via plant height. Thousand seeds weight had negative indirect effect (-0.216) on seed yield via number of capsules per plant. 

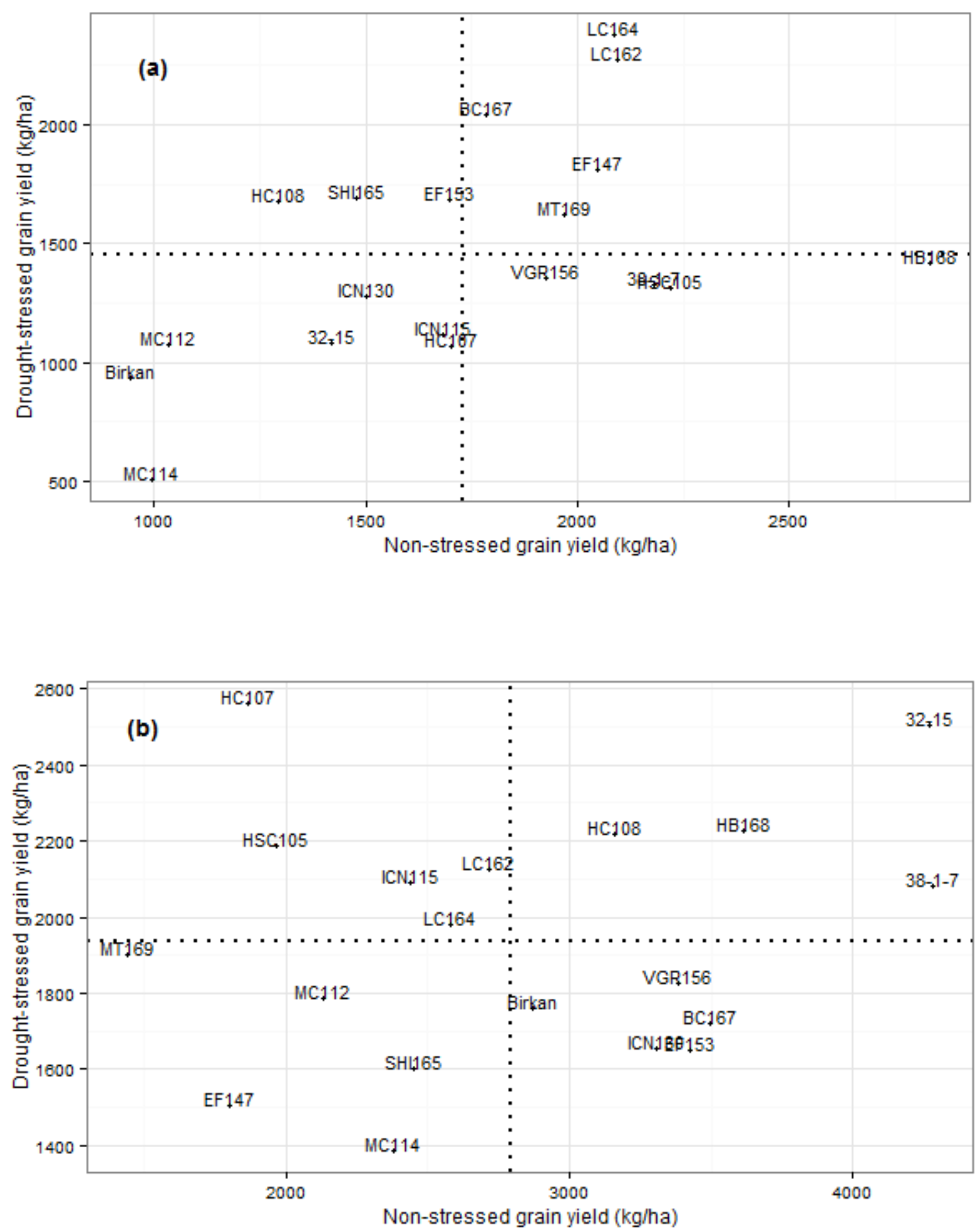

Fig. 1: Biplot for seed yield of 19 sesame genotypes in non-stressed and drought-stressed conditions in 2010 (a) and 2011 (b) Dotted lines represent overall yield mean in non-stressed (vertical) and drought-stressed (horizontal) conditions 

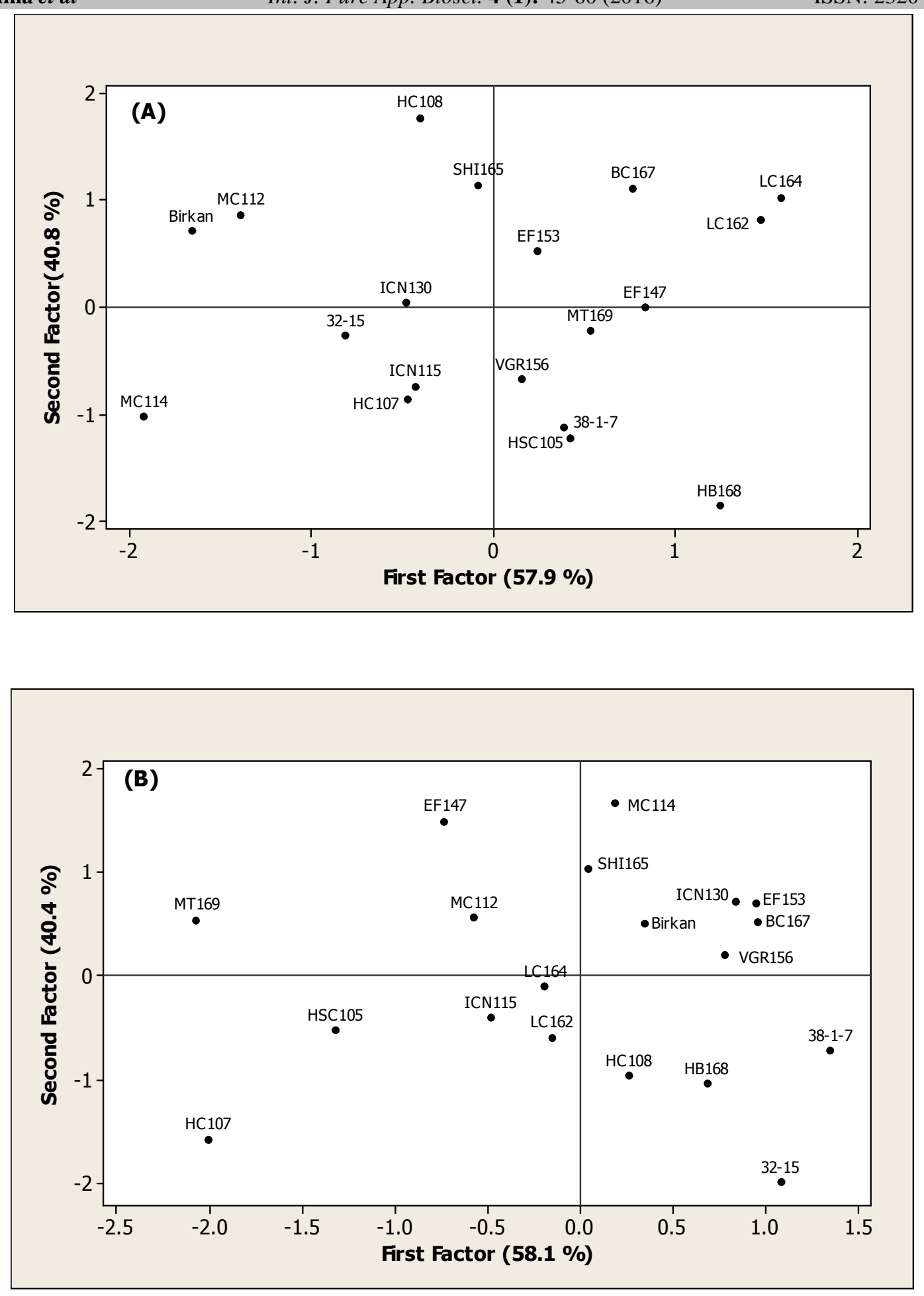

Fig. 2: Biplot based on first and second factor for 19 sesame genotypes during 2010 (A) and 2011 (B) 
Table 1. Yield component and yield of sesame genotypes grown under well watered (WW) and water stress (WS) conditions during 2010

\begin{tabular}{|c|c|c|c|c|c|c|c|c|c|c|c|c|c|c|c|c|}
\hline \multirow[t]{2}{*}{ Genotype } & \multicolumn{2}{|c|}{$\mathrm{PH}(\mathrm{cm})$} & \multicolumn{2}{|c|}{ SLFC(cm) } & \multicolumn{2}{|c|}{$\mathrm{NCP}$} & \multicolumn{2}{|c|}{ NSC } & \multicolumn{2}{|c|}{ NB } & \multicolumn{2}{|c|}{ Lcap (cm) } & \multicolumn{2}{|c|}{ 1000-SW (g) } & \multicolumn{2}{|c|}{ Yield $\left(\mathrm{kg} \mathrm{ha}^{-1}\right)$} \\
\hline & WW & WS & WW & WS & WW & WS & WW & WS & WW & WS & WW & WS & WW & WS & WW & WS \\
\hline $32-15$ & 93.3 & 72.5 & 27.7 & 20.6 & 102.6 & 58.0 & 55.0 & 59.0 & 4.2 & 4.3 & 2.7 & 3.0 & 3.7 & 3.3 & 1418.9 & 1083.3 \\
\hline $38-1-7$ & 98.2 & 82.0 & 27.8 & 25.0 & 138.7 & 100.2 & 71.0 & 48.0 & 4.7 & 5.0 & 3.6 & 2.8 & 2.9 & 3.2 & 2182.1 & 1325.1 \\
\hline BC167 & 92.3 & 87.9 & 20.9 & 23.8 & 124.4 & 71.0 & 76.3 & 71.0 & 3.5 & 4.9 & 3.5 & 3.1 & 3.7 & 3.6 & 1782.7 & 2041.6 \\
\hline Birkan & 83.5 & 74.5 & 17.7 & 17.6 & 80.0 & 52.6 & 61.7 & 56.0 & 3.4 & 3.0 & 3.2 & 2.7 & 3.7 & 4.2 & 943.5 & 935.7 \\
\hline EF147 & 93.3 & 90.8 & 19.9 & 18.4 & 90.7 & 99.1 & 71.3 & 77.3 & 3.6 & 4.7 & 3.5 & 3.9 & 3.8 & 3.7 & 2047.4 & 1809.3 \\
\hline EF153 & 102.9 & 90.9 & 24.9 & 25.6 & 102.4 & 103.9 & 76.7 & 68.3 & 3.9 & 6.4 & 3.0 & 3.0 & 3.0 & 3.2 & 1699.2 & 1686.1 \\
\hline HB168 & 109.6 & 82.2 & 26.0 & 23.0 & 152.1 & 85.8 & 60.3 & 52.0 & 4.6 & 6.1 & 3.2 & 2.9 & 3.6 & 3.5 & 2834.1 & 1419.6 \\
\hline $\mathrm{HC} 107$ & 89.1 & 72.3 & 25.0 & 20.8 & 89.9 & 52.2 & 64.7 & 75.0 & 3.9 & 3.9 & 2.9 & 3.4 & 3.5 & 3.4 & 1703.5 & 1070.7 \\
\hline HC108 & 101.2 & 94.1 & 24.2 & 23.8 & 120.7 & 116.8 & 69.7 & 37.0 & 4.7 & 6.8 & 2.8 & 2.7 & 3.2 & 3.3 & 1292.4 & 1678.2 \\
\hline HSC105 & 110.1 & 85.4 & 21.0 & 20.4 & 164.9 & 112.9 & 53.0 & 45.3 & 3.9 & 6.0 & 3.4 & 2.8 & 3.3 & 3.4 & 2218.8 & 1315.2 \\
\hline ICN115 & 88.9 & 76.2 & 18.0 & 16.1 & 108.9 & 76.0 & 64.3 & 57.3 & 3.7 & 4.2 & 3.5 & 3.2 & 3.6 & 3.6 & 1681.8 & 1116.0 \\
\hline ICN130 & 83.8 & 71.4 & 21.0 & 18.5 & 97.8 & 60.5 & 61.7 & 58.0 & 2.5 & 2.7 & 2.8 & 2.6 & 3.6 & 3.7 & 1500.5 & 1278.0 \\
\hline LC162 & 116.1 & 102.0 & 23.9 & 29.2 & 138.3 & 118.6 & 80.7 & 78.3 & 4.3 & 6.8 & 3.1 & 3.5 & 3.3 & 3.2 & 2093.4 & 2273.2 \\
\hline LC164 & 94.4 & 92.8 & 26.3 & 25.8 & 112.1 & 92.1 & 71.7 & 77.7 & 3.7 & 5.1 & 3.2 & 3.3 & 3.7 & 3.7 & 2086.1 & 2379.0 \\
\hline MC112 & 93.9 & 83.1 & 24.9 & 20.3 & 106.9 & 78.0 & 69.0 & 71.0 & 4.3 & 5.3 & 3.0 & 2.5 & 3.4 & 3.5 & 1033.7 & 1076.4 \\
\hline MC114 & 121.6 & 102.1 & 50.0 & 52.9 & 73.4 & 81.0 & 111.3 & 75.0 & 4.1 & 4.7 & 2.3 & 2.2 & 2.8 & 2.9 & 996.4 & 507.2 \\
\hline MT169 & 97.1 & 87.0 & 20.5 & 19.4 & 117.6 & 84.0 & 50.3 & 46.0 & 3.2 & 2.8 & 2.7 & 3.2 & 3.4 & 3.5 & 1970.9 & 1620.7 \\
\hline SHI165 & 95.5 & 80.2 & 25.7 & 24.6 & 134.4 & 104.9 & 57.0 & 45.0 & 3.6 & 3.7 & 2.5 & 2.4 & 3.6 & 3.5 & 1476.4 & 1690.0 \\
\hline VGR156 & 118.2 & 90.5 & 34.9 & 28.4 & 128.1 & 82.5 & 59.0 & 68.0 & 4.6 & 7.5 & 3.2 & 3.1 & 3.3 & 3.2 & 1926.6 & 1355.8 \\
\hline Mean & 99.1 & 85.2 & 25.3 & 23.9 & 114.9 & 85.8 & 67.6 & 61.3 & 3.9 & 5.0 & 3.1 & 3.0 & 3.4 & 3.4 & 1731.0 & 1455.8 \\
\hline $\operatorname{LSD}(5 \%)$ & 17.3 & 22.1 & 5.3 & 7.2 & 44.1 & 39.4 & 18.5 & 21.3 & 1.1 & 3.5 & 0.8 & 0.7 & 0.3 & 0.4 & 662.3 & 775.7 \\
\hline
\end{tabular}

SLFC: stem length to the first capsule, PH: plant height, NCP: number of capsules per plant, NSC: number of seed per capsule, LC: length of the capsule, SW: 1000-seed weight. 
Table 2. Yield components and yield of sesame genotypes grown under well watered (WW) and water stress (WS) conditions during 2011

\begin{tabular}{|c|c|c|c|c|c|c|c|c|c|c|c|c|c|c|}
\hline \multirow[t]{2}{*}{ Genotype } & \multicolumn{2}{|c|}{$\mathrm{PH}(\mathrm{cm})$} & \multicolumn{2}{|c|}{$\operatorname{SLFC}(\mathrm{cm})$} & \multicolumn{2}{|c|}{$\mathrm{NCP}$} & \multicolumn{2}{|c|}{ NSC } & \multicolumn{2}{|c|}{ NB } & \multicolumn{2}{|c|}{ 1000-SW (g) } & \multicolumn{2}{|c|}{ Yield $\left(\mathrm{kg} \mathrm{ha}^{-1}\right)$} \\
\hline & WW & WS & WW & WS & WW & WS & WW & WS & WW & WS & WW & WS & WW & WS \\
\hline $32-15$ & 176 & 137.8 & 85.6 & 69.3 & 132.0 & 80.4 & 60.5 & 70.7 & 5.2 & 2.5 & 3.6 & 3.4 & 4270.0 & 2503.5 \\
\hline $38-1-7$ & 185.2 & 142.5 & 76.9 & 87.9 & 434.4 & 67.5 & 74.2 & 70.5 & 5.8 & 2.6 & 2.9 & 3.3 & 4281.9 & 2080.0 \\
\hline BC167 & 214.5 & 141.6 & 117.2 & 66.4 & 129.7 & 52.6 & 72.6 & 74.9 & 4.6 & 2.1 & 3.8 & 3.8 & 3494.2 & 1720.2 \\
\hline Birkan & 124.5 & 116.8 & 31.2 & 37.6 & 76.3 & 79.4 & 74.4 & 78.6 & 2.9 & 3.5 & 3.7 & 3.9 & 2867.6 & 1759.2 \\
\hline EF147 & 148.2 & 112.8 & 61.5 & 50.3 & 89.6 & 50.7 & 73.6 & 72.4 & 3.2 & 2.6 & 3.8 & 3.7 & 1799 & 1505.4 \\
\hline EF153 & 218.7 & 151.2 & 122.8 & 94 & 151.0 & 96.6 & 68.8 & 74.5 & 4.1 & 4.2 & 2.9 & 3.4 & 3421.9 & 1649.2 \\
\hline HB168 & 185.1 & 134.6 & 87.7 & 62.4 & 122.2 & 73.7 & 61.7 & 66.9 & 3.5 & 2.9 & 3.7 & 3.6 & 3613.4 & 2227.0 \\
\hline HC107 & 142.4 & 131.5 & 72.9 & 70.7 & 95.6 & 68.7 & 63.0 & 67.1 & 4.8 & 1.9 & 3.7 & 3.4 & 1866.5 & 2561.4 \\
\hline HC108 & 186.6 & 147.6 & 105.7 & 72.8 & 111.5 & 84.1 & 70.3 & 72.3 & 5.0 & 2.5 & 3.3 & 3.2 & 3159.1 & 2216.4 \\
\hline HSC105 & 135.5 & 115.3 & 51.5 & 44.9 & 101.6 & 97.8 & 64.9 & 64.8 & 3.6 & 3.3 & 3.5 & 3.5 & 1964.5 & 2188.6 \\
\hline ICN115 & 124.6 & 117.9 & 42.8 & 39.8 & 96.6 & 90.6 & 74.9 & 68.2 & 3.9 & 2.9 & 3.7 & 3.3 & 2440.7 & 2090.8 \\
\hline ICN130 & 191.7 & 122.6 & 81.8 & 57.6 & 123.6 & 76.8 & 61.7 & 66.1 & 0.5 & 0.0 & 3.8 & 3.5 & 3305.5 & 1653.3 \\
\hline LC162 & 194.8 & 136.8 & 93.8 & 71.3 & 123.6 & 70.3 & 69.9 & 80.4 & 3.3 & 2.4 & 3.1 & 3.3 & 2715.2 & 2127.3 \\
\hline LC164 & 215.8 & 153.2 & 115.9 & 83.5 & 90.2 & 77.4 & 72.0 & 78.1 & 2.1 & 2.9 & 3.8 & 3.5 & 2581.6 & 1980.7 \\
\hline MC112 & 154.3 & 123.4 & 74.3 & 63.5 & 94.3 & 63.1 & 80.1 & 82.1 & 3.8 & 2.8 & 3.5 & 3.6 & 2134.5 & 1788.9 \\
\hline MC114 & 188.9 & 130.0 & 116.5 & 83.0 & 116.4 & 48.7 & 83.9 & 88.3 & 4.9 & 3.8 & 3.3 & 3.2 & 2381.7 & 1386.7 \\
\hline MT169 & 187.8 & 143.1 & 71.4 & 85.7 & 92.6 & 72.8 & 71.2 & 66.3 & 0.0 & 2.1 & 3.3 & 3.2 & 1441.1 & 1900.2 \\
\hline SHI165 & 172.2 & 131.1 & 87.1 & 62.6 & 90.8 & 81.1 & 57.5 & 71.9 & 1.9 & 1.5 & 3.5 & 3.3 & 2449.8 & 1599.9 \\
\hline VGR156 & 201.2 & 144.6 & 118.7 & 86.9 & 106.3 & 71.1 & 65.0 & 68.7 & 4.1 & 2.7 & 2.7 & 3.2 & 3383.7 & 1827.0 \\
\hline Mean & 176.2 & 133.4 & 85 & 67.9 & 125.2 & 73.9 & 69.5 & 72.8 & 3.5 & 2.6 & 3.46 & 3.4 & 2793.7 & 1935.1 \\
\hline $\operatorname{LSD}(5 \%)$ & 26.7 & 22.33 & 15.38 & 17.46 & 50.52 & 30.17 & 9.9 & 11.2 & 1.7 & 1.2 & 0.35 & 0.3 & 748.9 & 623.5 \\
\hline
\end{tabular}

SLFC: stem length to the first capsule, PH: plant height, NCP: number of capsules per plant, NSC: number of seed per capsule, LC: length of the capsule, SW: 1000 -seed weigh 
Table 3. Simple correlation coefficients between $Y_{p}, Y_{s}$ and drought tolerance/susceptibility indices of 19

sesame genotype in 2010

\begin{tabular}{lllllllll}
\hline & $\mathrm{Y}_{\mathrm{p}}$ & $\mathrm{Y}_{\mathrm{s}}$ & SSI & STI & MP & GMP & TOL & YI \\
\hline Ys & $0.494^{*}$ & & & & & & & \\
SSI & 0.317 & $-0.630^{* *}$ & & & & & & \\
STI & $0.810^{* *}$ & $0.894^{* *}$ & -0.235 & & & & & \\
MP & $0.868^{* *}$ & $0.861^{* *}$ & -0.174 & $0.985^{* *}$ & & & & \\
GMP & $0.833^{* *}$ & $0.891^{* *}$ & -0.231 & $0.988^{* *}$ & $0.997^{* *}$ & & & \\
TOL & $0.521^{*}$ & $-0.484^{*}$ & $0.937^{*}$ & -0.063 & 0.029 & -0.036 & & \\
YI & $0.492^{*}$ & $1.000^{* *}$ & $-0.632^{* *}$ & $0.894^{* *}$ & $0.860^{* *}$ & $0.890^{* *}$ & $-0.486^{*}$ & \\
YSI & -0.316 & $0.631^{* *}$ & $-1.000^{* *}$ & 0.237 & 0.176 & 0.232 & $-0.937^{* *}$ & $0.633^{* *}$
\end{tabular}

Y : yield in optimal conditions, $\mathrm{Y}_{\mathrm{s}}$ : yield under drought, SSI: stress susceptibility index, STI: stress tolerance index, MP: mean productivity, GMP: geometric mean productivity, TOL: tolerance, YI: yield index , YSI: yield stability index

Table 4. Simple correlation coefficients between $Y_{p}, Y_{s}$ and drought tolerance/susceptibility indices of 19

\begin{tabular}{lllllllll}
\multicolumn{10}{c}{ sesame genotype in 2011 } \\
\hline & $\mathrm{Y}_{\mathrm{p}}$ & $\mathrm{Y}_{\mathrm{S}}$ & SSI & STI & MP & GMP & TOL & YI \\
\hline YS & 0.186 & & & & & & & \\
SSI & $0.791^{* *}$ & -0.400 & & & & & & \\
STI & $0.900^{* *}$ & $0.576^{*}$ & $0.485^{*}$ & & & & & \\
MP & $0.940^{* *}$ & $0.511^{*}$ & $0.552^{*}$ & $0.988^{* *}$ & & & & \\
GMP & $0.907^{* *}$ & $0.578^{*}$ & $0.500^{*}$ & $0.994^{* *}$ & $0.994^{* *}$ & & & \\
TOL & $0.921^{* *}$ & -0.211 & $0.945^{* *}$ & $0.667^{* *}$ & $0.732^{* *}$ & $0.673^{* *}$ & & \\
YI & 0.190 & $1.000^{* *}$ & $-0.398^{* *}$ & $0.579^{* *}$ & $0.514^{*}$ & $0.581^{* *}$ & -0.208 & \\
YSI & $-0.789^{* *}$ & 0.402 & $-1.000^{* *}$ & $-0.481^{*}$ & $-0.550^{*}$ & $-0.497^{*}$ & $-0.944^{* *}$ & 0.400
\end{tabular}

$\mathrm{Y}_{\mathrm{p}}$ : yield in optimal conditions, $\mathrm{Y}_{\mathrm{s}}$ : yield under drought, SSI: stress susceptibility index, STI: stress tolerance index, MP: mean productivity, GMP: geometric mean productivity, TOL: tolerance, YI: yield index, YSI: yield stability index

Table 5. Ranks, ranks mean and standard deviation of ranks mean (SDR) of drought tolerance /susceptibility indices in 2010

\begin{tabular}{lcccccccccccc}
\hline Genotype & $\mathrm{Y}_{\mathrm{p}}$ & $\mathrm{Y}_{\mathrm{s}}$ & SSI & STI & MP & GMP & TOL & YI & YSI & Rank mean & SDR & FA1+FA2 \\
\hline $32-15$ & 15 & 15 & 12 & 16 & 16 & 16 & 11 & 15 & 12 & $14.22[16]$ & 1.99 & $-1.08[16]$ \\
$38-1-7$ & 3 & 11 & 16 & 8 & 8 & 8 & 17 & 11 & 16 & $10.89[10]$ & 4.70 & $-0.74[13]$ \\
BC167 & 9 & 3 & 2 & 5 & 5 & 5 & 3 & 3 & 2 & $4.11[3]$ & 2.20 & $1.88[3]$ \\
Birkan & 19 & 18 & 8 & 18 & 18 & 18 & 7 & 18 & 8 & $14.67[17]$ & 5.27 & $-0.95[15]$ \\
EF147 & 6 & 4 & 9 & 4 & 4 & 4 & 10 & 4 & 9 & $6.00[4]$ & 2.60 & $0.83[6]$ \\
EF153 & 11 & 6 & 7 & 9 & 9 & 9 & 8 & 6 & 7 & $8.00[7]$ & 1.66 & $0.77[7]$ \\
HB168 & 1 & 9 & 19 & 3 & 3 & 3 & 19 & 9 & 19 & $9.44[9]$ & 7.67 & $-0.61[12]$ \\
HC107 & 10 & 17 & 15 & 15 & 15 & 15 & 16 & 17 & 15 & $15.00[18]$ & 2.06 & $-1.33[18]$ \\
HC108 & 16 & 7 & 1 & 12 & 12 & 12 & 1 & 7 & 1 & $7.67[6]$ & 5.70 & $1.37[4]$ \\
HSC105 & 2 & 12 & 17 & 7 & 7 & 7 & 18 & 12 & 17 & $11.00[11]$ & 5.61 & $-0.80[14]$ \\
ICN115 & 12 & 14 & 14 & 14 & 13 & 14 & 14 & 14 & 14 & $13.67[15]$ & 0.71 & $-1.17[17]$ \\
ICN130 & 13 & 13 & 10 & 13 & 14 & 13 & 9 & 13 & 10 & $12.00[13]$ & 1.80 & $-0.44[9]$ \\
LC162 & 4 & 2 & 5 & 2 & 2 & 2 & 5 & 2 & 5 & $3.22[2]$ & 1.48 & $2.28[2]$ \\
LC164 & 5 & 1 & 4 & 1 & 1 & 1 & 2 & 1 & 4 & $2.22[1]$ & 1.64 & $2.60[1]$ \\
MC112 & 17 & 16 & 6 & 17 & 17 & 17 & 6 & 16 & 6 & $13.11[14]$ & 5.35 & $-0.52[11]$ \\
MC114 & 18 & 19 & 18 & 19 & 19 & 19 & 13 & 19 & 18 & $18.00[19]$ & 1.94 & $-2.93[19]$ \\
MT169 & 7 & 8 & 11 & 6 & 6 & 6 & 12 & 8 & 11 & $8.33[8]$ & 2.40 & $0.31[8]$ \\
SHI165 & 14 & 5 & 3 & 11 & 11 & 11 & 4 & 5 & 3 & $7.44[5]$ & 4.25 & $1.06[5]$ \\
VGR156 & 8 & 10 & 13 & 10 & 10 & 10 & 15 & 10 & 13 & $11.00[11]$ & 2.18 & $-0.51[10]$ \\
\hline
\end{tabular}


Table 6. Ranks, ranks mean and standard deviation of ranks mean (SDR) of drought tolerance /susceptibility indices in 2011

\begin{tabular}{lcccccccccccc}
\hline Genotype & $\mathrm{Y}_{\mathrm{p}}$ & $\mathrm{Y}_{\mathrm{s}}$ & SSI & STI & MP & GMP & TOL & YI & YSI & Rank mean & SDR & FA1+FA2 \\
\hline $32-15$ & 2 & 2 & 13 & 1 & 1 & 1 & 16 & 2 & 13 & $5.67[1]$ & 6.32 & $3.07[1]$ \\
$38-1-7$ & 1 & 8 & 18 & 2 & 2 & 2 & 19 & 8 & 18 & $8.67[8]$ & 7.70 & $2.07[2]$ \\
BC167 & 4 & 14 & 17 & 6 & 5 & 6 & 18 & 14 & 17 & $11.22[12]$ & 5.85 & $0.44[6]$ \\
Birkan & 9 & 13 & 12 & 12 & 10 & 12 & 12 & 13 & 12 & $11.67[14]$ & 1.32 & $-0.16[12]$ \\
EF147 & 18 & 18 & 6 & 19 & 19 & 19 & 4 & 18 & 6 & $14.11[18]$ & 6.62 & $-2.22[18]$ \\
EF153 & 5 & 16 & 19 & 8 & 7 & 8 & 17 & 16 & 19 & $12.78[16]$ & 5.65 & $0.25[8]$ \\
HB168 & 3 & 3 & 11 & 3 & 3 & 3 & 13 & 3 & 11 & $5.89[2]$ & 4.37 & $1.72[3]$ \\
HC107 & 17 & 1 & 1 & 13 & 13 & 13 & 1 & 1 & 1 & $6.78[4]$ & 6.96 & $-0.43[13]$ \\
HC108 & 8 & 4 & 9 & 4 & 4 & 4 & 10 & 4 & 9 & $6.22[3]$ & 2.68 & $1.24[4]$ \\
HSC105 & 16 & 5 & 3 & 14 & 14 & 14 & 3 & 5 & 3 & $8.56[7]$ & 5.73 & $-0.79[14]$ \\
ICN115 & 13 & 7 & 4 & 11 & 12 & 11 & 6 & 7 & 4 & $8.33[6]$ & 3.46 & $-0.07[10]$ \\
ICN130 & 7 & 15 & 16 & 9 & 8 & 9 & 15 & 15 & 16 & $12.22[15]$ & 3.83 & $0.12[9]$ \\
LC162 & 10 & 6 & 7 & 7 & 9 & 7 & 7 & 6 & 7 & $7.33[5]$ & 1.32 & $0.44[6]$ \\
LC164 & 11 & 9 & 8 & 10 & 11 & 10 & 8 & 9 & 8 & $9.33[9]$ & 1.22 & $-0.08[11]$ \\
MC112 & 15 & 12 & 5 & 16 & 16 & 16 & 5 & 12 & 5 & $11.33[13]$ & 5.00 & $-1.13[16]$ \\
MC114 & 14 & 19 & 14 & 17 & 17 & 17 & 11 & 19 & 14 & $15.78[19]$ & 2.68 & $-1.47[17]$ \\
MT169 & 19 & 10 & 2 & 18 & 18 & 18 & 2 & 10 & 2 & $11.00[11]$ & 7.55 & $-2.61[19]$ \\
SH165 & 12 & 17 & 10 & 15 & 15 & 15 & 9 & 17 & 10 & $13.33[17]$ & 3.12 & $-0.98[15]$ \\
VGR156 & 6 & 11 & 15 & 5 & 6 & 5 & 14 & 11 & 15 & $9.78[10]$ & 4.32 & $0.58[5]$ \\
\hline
\end{tabular}

Table 7. Results of factor analysis for drought tolerance/susceptibility indices and yields of 19 sesame

\begin{tabular}{|c|c|c|c|c|c|c|}
\hline \multicolumn{7}{|c|}{ genotypes in two years } \\
\hline \multirow{3}{*}{ Index } & \multicolumn{3}{|c|}{2010} & \multicolumn{3}{|c|}{2011} \\
\hline & \multicolumn{2}{|c|}{ Factor loading } & \multirow[t]{2}{*}{ Communalities } & \multicolumn{2}{|c|}{ Factor loading } & \multirow[t]{2}{*}{ Communalities } \\
\hline & FA1 & FA2 & & FA1 & FA2 & \\
\hline Yp & 0.875 & -0.459 & 1 & 0.915 & -0.368 & 1 \\
\hline Ys & 0.851 & 0.521 & 1 & -0.193 & -0.981 & 1 \\
\hline SSI & -0.142 & -0.987 & 1 & 0.97 & 0.216 & 0.983 \\
\hline STI & 0.987 & 0.100 & 0.985 & 0.672 & -0.718 & 1 \\
\hline MP & 0.998 & 0.029 & 1 & 0.733 & -0.664 & 0.999 \\
\hline GMP & 0.995 & 0.088 & 0.999 & 0.685 & -0.723 & 1 \\
\hline TOL & 0.045 & -0.973 & 1 & 0.987 & 0.023 & 1 \\
\hline YI & 0.85 & 0.523 & 1 & -0.19 & -0.982 & 1 \\
\hline YSI & 0.144 & 0.987 & 1 & -0.97 & -0.219 & 1 \\
\hline Variance & 5.2139 & 3.6687 & & 5.2254 & 3.6363 & \\
\hline Variance $\%$ & 0.579 & 0.408 & & 0.581 & 0.404 & \\
\hline Cumulative & 0.579 & 0.987 & & 0.581 & 0.985 & \\
\hline
\end{tabular}


Table 8. Path coefficients of measured traits in mutant germplasm of sesame

\begin{tabular}{lclr}
\hline $\begin{array}{l}\text { Stem length to the first capsule vs } \\
\text { yield }\end{array}$ & $\mathrm{r}=-0.195$ & Number of seeds per capsule vs yield & $\mathrm{r}=0.157$ \\
Direct effect & -0.283 & Direct effect & 0.176 \\
Indirect effect via PH & 0.221 & Indirect effect via SLFC & -0.089 \\
Indirect effect via NCP & 0.100 & Indirect effect via PH & 0.106 \\
Indirect effect via NSC & 0.056 & Indirect effect via NCP & -0.111 \\
Indirect effect via LC & -0.092 & Indirect effect via LC & 0.099 \\
Indirect effect via SW & -0.189 & Indirect effect via SW & -0.021 \\
& & & \\
Plant height vs yield & $\mathrm{r}=0.409$ & Capsule length vs yield & 0.533 \\
Direct effect & 0.332 & Direct effect & 0.233 \\
Indirect effect via SLFC & -0.188 & Indirect effect via SLFC & 0.112 \\
Indirect effect via NCP & 0.348 & Indirect effect via PH & 0.029 \\
Indirect effect via NSC & 0.056 & Indirect effect via NCP & 0.032 \\
Indirect effect via LC & 0.021 & Indirect effect via NSC & 0.075 \\
Indirect effect via SW & -0.142 & Indirect effect via SW & 0.055 \\
Number of cap. per plant vs yield & $\mathrm{r}=0.531$ & Thousand seeds weight vs yield & $\mathrm{r}=0.132$ \\
Direct effect & 0.519 & Direct effect & 0.276 \\
Indirect effect via SLFC & -0.055 & Indirect effect via SLFC & 0.193 \\
Indirect effect via PH & 0.223 & Indirect effect via PH & -0.171 \\
Indirect effect via NSC & -0.038 & Indirect effect via NCP & -0.216 \\
Indirect effect via LC & 0.015 & Indirect effect via NSC & -0.013 \\
Indirect effect via SW & -0.115 & Indirect effect via LC & 0.046
\end{tabular}

\footnotetext{
SLFC: stem length to the first capsule, PH: plant height, NCP: number of capsules per plant, NSC: number of seed per capsule, LC: length of the capsule, SW: 1000-seed weight.
}

\section{DISCUSSION}

In sesame breeding, the goal is to attain high seed yield. The later character is therefore the most reliable measure for selecting for drought tolerance. Venuprazad et al. ${ }^{35}$ stated that direct selection under dry season stress also gave similar response as under naturally occurring wet season stress. But our results are in contradiction with this later author according to a high genotype $\mathrm{x}$ season interaction (data not shown). In our research conditions, yield was significantly lower in drought-stressed conditions relative to nonstressed conditions. However, contrary to what was expected, some genotypes performed better under moderate drought-stressed conditions than in non-stressed conditions. Similar findings were reported by Urrea et al. ${ }^{31}$ with the dry bean (Phaseolus vulgaris L.) cultivar SER 22 which performed well under drought-stressed conditions, but below average under non-stressed conditions. These genotypes are classified in the class $\mathrm{C}$ according to Fernandez ${ }^{14}$.

In 2010, genotypes LC 164, LC 162, BC 167, EF 147 and MT 169 had the highest grain yield under both DS and NS environments, while in 2011 HC 108, 32-15, HB 168 and 38-1-7 had the highest grain yield irrespective to the environments. These genotypes could be therefore classified in the group A based on Fernandez ${ }^{14}$ model. In contrast ICN 130, MC 112, 32-15, ICN 115, HC 107, Birkan, MC 114 and MT 169, MC 112, EF 147, SHI 165, MC 114 perform poorly in both DS and NS conditions in the first and second year, respectively, and were classified as group D.

HC 108, SHI 165, EF 153 and HC 107, LC 162, LC 164, HSC 105, ICN 115 perform favorably only when grown under DS conditions in 2010 and 2011, respectively, and were classified in the group C contrary to VGR 156, 38-1-7, HSC 105, HB 168 and Birkan, VGR 156, BC 167, ICN 130 and EF 153 which perform favorably only in NS environment and thus were classified in the group B according to Fernande $\mathrm{z}^{14}$. 
To determine the most suitable drought tolerant criteria, the correlation between $Y_{\mathrm{p}}, \mathrm{Y}_{\mathrm{s}}$ and other drought tolerance indices was computed. In other words, correlation studies between yield and drought tolerances indices can be a good criteria for screening the best genotypes and indices used ${ }^{13}$. Therefore, a discriminatory index must have a significant correlation with grain yield under both stressed and nonstressed environments ${ }^{21}$.

STI, MP and GMP had significant and positive correlation with both yield under drought-stressed (Ys) and non-stressed environments in both two years. These results confirmed those of Abdolshahi et al. ${ }^{1}$ stating that STI, MP, GMP and YI appeared to be the most efficient selection indices for identifying high yielding genotypes for both normal and drought-stressed environments.

GMP and STI had high correlation with MP and therefore STI, GMP and MP could produce similar results. Fernandez ${ }^{14}$ stated that STI is estimated based on GMP and the correlation between STI and GMP is equal to 1 . Akçura et $a .^{2}$ reported that YI, YSI, STI, GMP were significantly and positively correlated with stress yield and these indices showed that cultivars may be ranked only on the basis of their yield under stress and so does not discriminate genotypes of group A.

Based on STI, GMP and MP, LC 164 was the best drought tolerant genotype in the first year. Thus, it could be concluded that selection based on these indices results in genotypes with high yield potential as stated by Abdolshahi et al. ${ }^{1}$. STI is effective in selecting higher-yielding lines in both stressed and nonstressed environments and could thus discriminates group A with others (B,C,D). The higher the value of STI of a given genotype, the higher its stress tolerance and yield potential ${ }^{14}$. It is clear that STI is not efficient in selecting low yield lines even though their reduction percentage of seed yield across environments is lower. It's the case of genotypes hsc 105 with yield reduction percentage ( $\mathrm{PR}=8 \%$, data not shown), mc112 ( $\mathrm{PR}=10 \%)$ and mutant-cultivar Birkan ( $\mathrm{PR}=29 \%)$.

The correlation between $Y_{p}$ and $Y_{s}$ was positively significant $\left(r=0.49^{*}\right)$ in 2010 but not in 2011. In other words, sesame genotypes with high yield potential may not necessarily perform favorably in droughtstressed environments. This result is supported by Belko et al. ${ }^{6}$ who reported poor relationship between grain yield under NS and DS environments in both short and medium duration cowpea genotypes and opposed those claimed by certain authors who stated that genotypes with high yield potential are like to have high yield in drought-stressed conditions.

The correlation between $\mathrm{YI}$ and $\mathrm{Y}_{\mathrm{s}}$ is equal to 1 . Therefore, $\mathrm{YI}$ is a suitable criterion for drought tolerance. TOL had high positive correlation with $Y_{p}$ and negative ones with $Y_{s}$. Fernandez ${ }^{14}$ stated that selection based on TOL favours genotypes with low yield potential in non-stressed conditions and high yield under stress conditions. Based on these results STI, GMP and MP favour genotypes with high yield potential while TOL favours genotypes with low yield potential. Thus, different indices would not result in the same ranking.

Factor analysis and the mean ranking approach were used for selecting the suitable drought tolerant material across environments and years. These methods have the advantage to use all drought tolerance indices simultaneously. In the first year, LC 164 and LC 162 were identified as the best drought tolerant genotypes according to the two ranking methods.

In 2011, cultivar 32-15 was ranked first according to FA and the mean ranks method and thus identified as the most drought tolerant genotype. This ranking method was also used to identify drought-tolerant cultivars of bread wheat ${ }^{13}$, spring canola cultivars ${ }^{19}$ and $\operatorname{Corn}^{23}$.

Genotypes ranking according to their drought tolerance/susceptibility were thus affected across the seasons. The two experiments were conducted in two different seasons contrasting for weather conditions. In 2010, the experiment was conducted in a hot and dry season under irrigated conditions while the second year corresponds to the normal rainy season in the semi-arid tropic. In other words, this seasonality may interact as a genotype by environment effect. The cultivar 32-15 is a well locally adapted variety grown largely by Senegalese sesame growers in rainfed conditions. All other genotypes were induced by mutagenesis from 32-15 and 38-1-7 as parents. 
Path coefficient analysis in the present study showed that number of capsules per plant, plant height, thousand seed weight and length of the capsules were the most important components with direct and positive influence on seed yield in drought stress conditions. This was in accordance with the findings of Uzun and Cagirgan $^{34}$ and Yingzhong and Yishou ${ }^{37}$. Plant height is the character most contributing to seed yield in sesame because the species has an indeterminate growth habit ${ }^{32}$. Although this character prevents mechanized harvesting and the expansion of its cultivation, plant height may favoured high branching and capsule production. Thus, plant height, number of capsules per plant, and length of the capsules should be considered in selection for obtaining high- yielding sesame cultivars in drought-stressed environments. This was supported by the fact that plant height has a positive indirect effect (Table 8) on seed yield via number of capsules per plant. In other studies ${ }^{27,37}$ higher number of capsules per plant and plant height showed a positive indirect effect on seed yield.

The correlation and the direct effect of stem length to the first capsule on seed yield were negative. However, the stem length to the first capsule had a positive indirect effect on seed yield via plant height with which it was strongly correlated. Thus, in indirect selection for high-yielding sesame cultivars, plant height and stem length to the first capsule traits should be considered together as a selection criterion.

\section{Acknowledgements}

This study is an unpublished part of the first author Ph.D. thesis supported by the Deutscher Akademischer Aus-tauschdienst (DAAD), which is gratefully acknowledged.

The first author thanks technicians from CNRA Bambey (Senegal) for field assistance.

\section{REFERENCES}

1. Abdolshahi Roohollah, Safarian Abdorahim, Nazari Maryam, Pourseyedi Shahram, Mohamadi-Nejad Ghasem, Screening drought-tolerant genotypes in bread wheat Triticum aestivum L.) using different multivariate methods. Archives of Agronomy and Soil Science, 59(5): 685-704 (2013).

2. Akçura, M., Partigoç, F., Kaya, Y., Evaluating of drought stress tolerance based on selection indices in turkish bread wheat landraces. Journal of Animal \& Plant Sci., 21(4): $700-709$ (2011).

3. Arslan, C., Uzun, B., Ulger, S., Cagirgan, M.I., Determination of Oil Content and Fatty Acid Composition of Sesame Mutants Suited for Intensive Management Conditions. J. Am. Oil Chem. Soc. 84: 917-920 (2007).

4. Ashri, A., Sesame (Sesamum indicum L.). In: Singh RJ (ed) Genetics Resources, Chromosome Engineering, and Crop Improvement, Vol.4, Oilseed Crops, CRC Press, Boca Raton, FL, USA (2007).

5. Bänziger, M., Lafitte, H.R., Efficiency of secondary traits for improving maize for low-nitrogen target environments. Crop Science, 37: 1110-1117 (1997).

6. Belko, N., Cisse N., Diop, Ndeye N., Zombre, G., Thiaw S., Muranaka S., Ehlers, Jeffrey. D., Selection for Postflowering Drought Resistance in Short and Medium- duration Cowpeas Using Stress Tolerance Indices. Crop Sci., 54: 1-9 (2014).

7. Boureima, S., Diouf, M., Silme, R.S., Diop, T., Van Damme, P., Cagirgan, M.I., Radiosensitivity of African sesame to gamma rays. Turkish J. of Field Crops, 14(2): 181-190 (2009).

8. Dadbakhsh, A., Yazdan-Sepas, A., Evaluation of drought tolerance indices for screening bread wheat genotypes in end-season drought stress conditions. Adv Environ Biol., 5(6): 1040-1045 (2011).

9. Dewey, D.R., Lu, K.H., A correlation and path analysis of components of crested wheat grass seed production. Agron. J., 51: 515-518 (1959).

10. Diouf, M., Boureima, S., Diop, T., Cagirgan, M.I., Gamma Rays-induced mutant spectrum and frequency in sesame. Turkish J. of Field Crops, 15(1): 99-105 (2010).

11. Erbas, M., Sekerci, H., Gül, S., Furat, S., Yol, E., Uzun, B., Changes in total antioxidant capacity of sesame (Sesamum sp.) by variety. Asian J. Chem., 21: 5549-5555 (2009).

12. FAO, 2015. Available at: http://www.fao.org./ 
13. Farshadfar, E., Moradi Z., Elyasi P., Jamshidi B., Chaghakabodi, R., Effective selection criteria for screening drought tolerant landraces of bread wheat (Triticum aestivum L.). Annals of Biological Research, 3(5): 2507-2516 (2012).

14. Fernandez, G.C.J., Effective selection criteria for assessing plant stress tolerance. In: Adaptation of food crop temperature water stress, proceedings of an international symposium, Taïwan, pp 257-269 (1992).

15. Fischer, R.A., Maurer, R., Drought resistance in spring wheat cultivars: I. Grain yield responses. Aust. J. Agric. Res., 29: 897-912 (1978).

16. Fukai, S., Cooper, M., Development of drought-resistant cultivars using physio-morphological traits in rice. Field Crops Research, 40: 67-86 (1995).

17. Golabadi, M., Arzani A., Sam, M-M., Assessment of drought tolerance in segregating populations in durum wheat. Afr. J. Agr. Res., 5: 162-171 (2006).

18. Hao, Z.F., Li, X.H., Su, Z.J., Xie, C.X., Li, M.S., Liang, X.L., Weng, J.F., Zhang, D.G., Li, L., Zhang, S.H., A proposed selection criterion for drought resistance across multiple environments in maize. Breed Sci., 61: 101-108 (2011).

19. Khalili, M., Naghavi, M.R., Pouraboughadareh, A.R., Talebzadeh, J., Evaluating of drought stress tolerance based on selection indices in spring canola cultivars (Brassica napus L.). JAS 4(11): 78-85 (2012).

20. Lafitte, R., Blum, A., Atlin, G., Using secondary traits to help identify drought-tolerant genotypes. In Breeding Rice for Drought-Prone Environments, Fischer K.S., R. Lafitte, S. Fukai, G. Atlin, and B. Hardy, (eds.), Los Banos, Philipines, (2003).pp. 37-61

21. Mitra, J., Genetics and genetic improvement of drought resistance in crop plants. Curr. Sci. India, 80: 758-762 (2001).

22. Mohammadi, M., Karimzade, R., Abdipour, M., Evaluation of drought tolerance in bread wheat genotypes under dryland and supplemental irrigation conditions. Aust. J. Crop Sci. 5(4): 487-493 (2011).

23. Naghavi, Mohammad R., Pouraboughadareh, A., Khalili, M., Evaluation of Drought Tolerance Indices for Screening Some of Corn (Zea mays L.) Cultivars under Environmental Conditions. Not. Sci. Biol., 5(3): 388-393 (2013).

24. Ouk, M., Basnayake, J., Tsubo, M., Fukai, S., Fischer, K.S., Cooper, M., Nesbitt, H., Use of drought response index for identification of drought tolerant genotypes in rainfed lowland rice. Field Crops Res., 99: 48-58 (2006).

25. Rosielle, A.A., Hamblin, J., Theoretical aspects of selection for yield in stress and non-stress environment. Crop Sci., 21: 943-946 (1981).

26. Singh, B.B., H.A. Ajeigbe, S.A. Tarawali, S. Fernandez-Rivera, Abubakar M., Improving the production and utilization of cowpea as food and fodder. Field Crops Res., 84: 169-177 (2003).

27. Sumathi, P., Muralidharan, V., Manivannan, N., Trait association and path coefficient analysis for yield and yield attributing traits in sesame (Sesamum indicum L). Madras Agric. J., 94: 174-178 (2007).

28. Teran, H., Singh, S.P., Comparison of sources and lines selected for drought resistance in common bean. Crop Sci., 42: 64-70 (2002).

29. Toker, C., Cagirgan, M.I., Selection criteria in Chickpea (Cicer arietinum L.). Acta Agric Scand, Sect B, Soil and Plant Sci., 53: $42-45$ (2003).

30. Toker, C., Evaluation of yield criteria with phenotypic correlations and factor analysis in Chickpea. Acta Agric Scand, Sect B, Soil and Plant Sci., 54: 45-48 (2004).

31. Urrea, Carlos A., Dean Yonts, C., Drew J. Lyon, K., Ann, E., Selection for Drought Tolerance in Dry Bean Derived from the Mesoamerican Gene Pool in Western Nebraska. Crop Sci., 49: 2005-2010 (2009).

32. Uzun, B., Cagirgan, M.I., Identification of molecular markers linked to determinate growth habit in sesame. Euphytica 166: 379-384 (2009). 
33. Uzun, B., Arslan, Ç., Furat, S., Variation in fatty acid compositions, oil content and oil yield in a germplasm collection of sesame (Sesamum indicum L.). J. Am. Oil Chem. Soc., 85: 1135-1142 (2008).

34. Uzun, B., Cagirgan, M.I., Path-coefficient analysis for seed yield and related characters in a population of determinate and indeterminate types of sesame (Sesamum indicum L.) Turk. J. Field Crops 6: 76-80 (2001).

35. Venuprasad, R., Lafitte, H. R., Atlin, G.N., Response to Direct Selection for Grain Yield under Drought Stress in Rice. Crop Sci., 47: 285-293 (2007).

36. Wright, S., Correlation and causation. Journal of Agricultural Research, 20: 557-585 (1921).

37. Yingzhong, Z., Yishou, W., Genotypic correlations and path coefficient analysis in sesame. Sesame and Safflower News 17:10-12 (2002).

38. Yol, E., Karaman, E., Furat, Ş., Uzun, B., Assessment of selection criteria in sesame by using correlation coefficients, path and factor analyses. A.J.C.S. 4(8): 598-602 (2010). 